DE OLIVEIRA SALES, Suelen Bianca; AGUIAR ESTEVES, Mariana. Regulação econômica por incentivos e seus reflexos nas agências reguladoras. Revista Eletrônica Direito e Política, Programa de Pós-Graduação Stricto Sensu em Ciência Jurídica da UNIVALI, Itajaí, v.16, n.1, 10 quadrimestre de 2021. Disponível em: www.univali.br/direitoepolitica - ISSN 1980-7791

\title{
REGULAÇÃO ECONÔMICA POR INCENTIVOS E SEUS REFLEXOS NAS AGÊNCIAS REGULADORAS
}

\author{
ECONOMIC REGULATION BY INCENTIVES AND THEIR IMPACT ON \\ REGULATORY AGENCIES
}

\author{
Suelen Bianca de Oliveira Sales ${ }^{1}$ \\ Mariana Aguiar Esteves ${ }^{2}$
}

\section{RESUMO}

O presente trabalho possui como escopo fazer uma breve revisão da leitura sobre a regulação econômica, sob as perspectivas das teorias de regulação econômica destacando a promoção do bem-estar econômico e social pelo governo por meio da política regulatória. O modelo "estado regulador" pode buscar em meio às políticas públicas maior eficiência, modicidade na tarifação, e melhora da qualidade e quantidade na prestação dos serviços públicos. O regime de incentivos e garantias de rentabilidade a longo prazo, muitas vezes torna os serviços públicos pouco atrativos para empreendedores privados, todavia o marco regulatório do modelo de regulação por incentivos é justamente compatibilizar esses interesses conflitantes, com o auxílio de normas que beneficiem empresas com desempenho mais eficiente e penalizem as ineficientes.

PALAVRAS-CHAVE: Regulação Econômica; Teoria Econômica de Regulação; Políticas Públicas; Eficiência; Sanções Positivas.

\section{ABSTRACT}

The scope of this paper is to make a brief review of the reading on economic regulation, from the perspectives of the theories of economic regulation highlighting the promotion of economic and social welfare by the government through regulatory policy. The "regulatory state" model can seek, in the midst of public policies, greater efficiency, modicity in pricing, and improvement in quality

\footnotetext{
1 Advogada, Graduada em Direito pelo Instituto de Educação Superior de Brasília/IESB, PósGraduada em Direito Constitucional pela Anhanguera. Mestranda em Direto pela Universidade Nove de Julho na linha de pesquisa Empresa, Sustentabilidade e Funcionalização do Direito. Especialista em Direito Empresarial e Tributário. Professora, Palestrante e Membro da Comissão de Assuntos Tributário da OAB/DF. E-mail: prof.suelensales@gmail.com.

2 Advogada, Graduada em Direito pela Universidade Federal de Rondônia - UNIR. Pós-Graduada em Direito Civil e Processo Civil pela Fundação Getúlio Vargas - FGV. Mestranda pelo Programa de Mestrado em Direito da Universidade Nove de Julho - UNINOVE, linha de pesquisa Justiça, Empresa e Sustentabilidade. E-mail: mariiesteves@hotmail.com.
} 
VIANA CUSTÓDIO, André; DA ROSA MOREIRA, Rafael Bueno. Revitimização de crianças e adolescentes em inquirições judiciais e violência institucional. Revista Eletrônica Direito e Política, Programa de Pós-Graduação Stricto Sensu em Ciência Jurídica da UNIVALI, Itajaí, v.16, n.1, ${ }^{\circ}$ quadrimestre de 2021. Disponível em: www.univali.br/direitoepolitica - ISSN 1980-7791

and quantity in the provision of public services. The system of incentives and guarantees of long-term profitability often makes public services unattractive to private entrepreneurs, but the regulatory framework of the incentive regulation model is precisely to reconcile these conflicting interests with the aid of standards that benefit companies with more efficient performance and penalize inefficient ones.

KEYWORDS: Economic Regulation; Economic Theory of Regulation; Public Policies; Efficiency; Positive Sanctions.

\section{INTRODUÇÃO}

O presente artigo trata sobre regulação econômica, sendo este tema estudado nos campos da Economia, Direito, e Ciência Política. Cada seara apontada apresenta suas nuances e não restam dúvidas que se trata de um tema complexo.

O presente artigo tem como escopo analisar o tema regulação, sob uma perspectiva econômica e jurídica, apresentando argumentos das teorias econômicas da regulação vislumbrando a utilização dos mecanismos regulatórios que possam trazer eficiência e mesmo assim garantir bem-estar econômico e social, apesar da premissa se apresentar contraditória, haja vista nossa moderna economia capitalista.

No Brasil o processo de privatização e regulação se iniciou há mais de duas décadas com objetivo de criar um dinamismo nos setores monopolizados, não podendo se esquecer da questão fiscal a ser enfrentada.

O texto provoca para a reflexão sobre os instrumentos governamentais na implementação de políticas públicas, nas quais as agências reguladoras possuem ativo e relevante papel e que a administração tem notáveis reformas na busca da melhora da gestão governamental.

A regulação por incentivo possibilita incorporar maior qualidade ao fornecimento de serviços e produtos, sendo o fator das sanções positivas, um grande aliado na regulação econômica e social. 
VIANA CUSTÓDIO, André; DA ROSA MOREIRA, Rafael Bueno. Revitimização de crianças e adolescentes em inquirições judiciais e violência institucional. Revista Eletrônica Direito e Política, Programa de Pós-Graduação Stricto Sensu em Ciência Jurídica da UNIVALI, Itajaí, v.16, n.1, 10 quadrimestre de 2021. Disponível em: www.univali.br/direitoepolitica - ISSN 1980-7791

O presente trabalho se propõe a realizar uma pesquisa básica acerca da Regulação Econômica por Incentivo no Brasil, com o intuito de proporcionar ao leitor informações sobre as posições doutrinárias e artigos científicos acerca do tema. Quanto à sua natureza, a pesquisa adotará uma abordagem qualitativa e será realizada pesquisa exploratória.

Essencialmente, realizaremos um levantamento bibliográfico, de forma que as fontes utilizadas para a pesquisa se concentram na consulta à bibliografia sobre o tema, priorizando o enfoque no Direito Econômico, fundamentalmente na Regulação Econômica por Incentivos. Junto à pesquisa bibliográfica stricto sensu, realizaremos também consulta à legislação pertinente. Serão ainda utilizados outros recursos documentais, entre eles artigos e periódicos, através de consultas a sítios da internet.

\section{REGULAÇÃo}

O termo "regulação" tem origem nos países de língua inglesa e se refere à atividade desenvolvida pelo Estado. Contudo, a terminologia no Direito brasileiro tem correspondência na expressão regulamentação que possui uma aplicação de cunho abstrato e geral ${ }^{3}$.

Na Economia, o vernáculo "Regulacion" está envolvido pela atmosfera teórica, metodológica e ideológica sendo definido em diferentes aspectos nas teorias de regulação econômica conforme destaca os autores Gary Becker ${ }^{4}$, Richard Posner $^{5}$, Ronald Coase ${ }^{6}$ e George Stigler ${ }^{7}$, dentre outros. Esses autores não podem ser reunidos em uma só corrente de pensamento, mas é possível encontrar uma série de similitudes nas suas teorias.

\footnotetext{
3 JUSTEN FILHO, Marçal. O direito das agências reguladoras independentes. São Paulo: Dialética, 2002. p.15-16.

4 BECKER, Gary S. A theory of competition among pressure group for political influence. Quarterly Jornal of Economics, no. 98,1983 p. 371-400

5 POSNER, Richard A. Theories of economic regulation. NBER,1974.p.12-13. (Working paper, n.41).

6 COASE, Ronald H. The Problem of Social Cost. The Journal of Law and Economicas. V. 3, p.1. 1960.

7STIGLER, George J. The Theory economic regulation. The Bell Journad of Economics and Management Science. V. 2, n.1.p.3, Spring, 1971.
} 
VIANA CUSTÓDIO, André; DA ROSA MOREIRA, Rafael Bueno. Revitimização de crianças e adolescentes em inquirições judiciais e violência institucional. Revista Eletrônica Direito e Política, Programa de Pós-Graduação Stricto Sensu em Ciência Jurídica da UNIVALI, Itajaí, v.16, n.1, 10 quadrimestre de 2021. Disponível em: www.univali.br/direitoepolitica - ISSN 1980-7791

No que tange ao Direito Econômico com foco nas Agências Reguladoras, a definição de Alexandre Santos de Aragão $^{8}$ do termo regulação ora trabalhada, in verbis:

A regulação estatal da economia é um conjunto de medidas legislativas, administrativas e convencionais, abstratas ou concretas, pelas quais o Estado, de maneira restritiva da liberdade privada ou meramente indutivas, determina, controla ou influencia o comportamento dos agentes econômicos, evitando que lesem os interesses sociais definidos no marco da Constituição e orientandoos em direções socialmente desejáveis.

$\mathrm{Na}$ visão da Maria Sylvia Zanello Di Pietro, define-se que a regulação se enquadra no "conjunto de regras de conduta e de controle da atividade econômica pública e privada e das atividades sociais não exclusivas do Estado, com a finalidade de proteger o interesse público9".

No quadro político, foi necessário proceder uma ampla reforma constitucional para alcançar altos níveis de concorrência no setor público e privado, iniciada com a Emenda Constitucional $n^{\circ} 5 / 95^{10}$ que permitiu que o gás canalizado fosse distribuído por concessionárias particulares.

A partir da Emenda Constitucional $n^{0} 6 / 95^{11}$ os setores de pesquisa de lavra de recursos minerais deixaram de ser exclusivos de empresas brasileiras. E na

\footnotetext{
${ }^{8}$ ARAGÃO, Alexandre Santos de. Agências reguladoras e a evolução do direito administrativo econômico. Rio de Janeiro: Forense, 2004. P.37

${ }^{9}$ DI PIETRO, Maria Sylvia Zanello. Limites da função reguladora das agências diante do princípio da legalidade. In: DI PIETRO, Maria Sylvia Zanello (Coord.) Direito regulatório: temas polêmicos. 2ed. Belo Horizonte: Fórum, 2004.p.37

10 Emenda Constitucional n 5, de 15 de agosto de 1995: Artigo único. O parágrafo 20 do art. 25 da Constituição Federal passa a vigorar com a seguinte redação:

"Cabe aos Estados explorar diretamente, ou mediante concessão, os serviços locais de gás canalizado, na forma da lei, vedada a edição de medida provisória para a sua regulamentação.".

${ }^{11}$ Emenda Constitucional $n^{\circ}$ 6, de 15 de agosto de 1995:

Art. $1^{\circ} \mathrm{O}$ inciso IX do art. 170 e o $\S 1^{\circ}$ do art. 176 da Constituição Federal passam a vigorar com a seguinte redação:

(...)

Art. 176

(...)

$\S 1^{\circ} \mathrm{A}$ pesquisa e a lavra de recursos minerais e o aproveitamento dos potenciais a que se refere o "caput" deste artigo somente poderão ser efetuados mediante autorização ou concessão da União, no interesse nacional, por brasileiros ou empresa constituída sob as leis brasileiras e que
} 
VIANA CUSTÓDIO, André; DA ROSA MOREIRA, Rafael Bueno. Revitimização de crianças e adolescentes em inquirições judiciais e violência institucional. Revista Eletrônica Direito e Política, Programa de Pós-Graduação Stricto Sensu em Ciência Jurídica da UNIVALI, Itajaí, v.16, n.1, 10 quadrimestre de 2021. Disponível em: www.univali.br/direitoepolitica - ISSN 1980-7791

Emenda Constitucional $n^{\circ} 7 / 95^{12}$ uma série de restrições foram suprimidas do texto constitucional referente à legislação regulamentadora de armadores nacionais e navios de bandeira brasileira.

Com o advento da Emenda Constitucional $n^{\circ} 8 / 95^{13}$ veio a ser permitido que empresas privadas do setor telecomunicações tivessem acesso por meio de autorizações, concessões ou permissões, lembrando que antes da referida emenda apenas era possível a delegação dos serviços de telecomunicação.

Ainda nesse sentido, também foi objeto de reforma constitucional o regime de monopólio, com a Emenda Constitucional n 9/95 foi permitida a flexibilização do monopólio estatal, que foi coroada pela Lei Federal $n^{\circ} 9.478 / 97^{14}$.

tenha sua sede e administração no País, na forma da lei, que estabelecerá as condições específicas quando essas atividades se desenvolverem em faixa de fronteira ou terras indígenas."

(...)

Art. 30 Fica revogado o art. 171 da Constituição Federal.

12 Emenda Constitucional $n^{\circ} 7$, de 15 de agosto de 1995:

Art. $1^{\circ} \mathrm{O}$ art. 178 da Constituição Federal passa a vigorar com a seguinte redação:

"Art. 178. A lei disporá sobre a ordenação dos transportes aéreo, aquático e terrestre, devendo, quanto à ordenação do transporte internacional, observar os acordos firmados pela União, atendido o princípio da reciprocidade.

Parágrafo único. Na ordenação do transporte aquático, a lei estabelecerá as condições em que o transporte de mercadorias na cabotagem e a navegação interior poderão ser feitos por embarcações estrangeiras."

${ }^{13}$ Emenda Constitucional n० 8, de 15 de agosto de 1995:

Art.10 $\mathrm{O}$ inciso XI e a alínea "a" do inciso XII do art. 21 da Constituição Federal passam a vigorar com a seguinte redação: "Art. 21. Compete à União:

(...)

XI - explorar, diretamente ou mediante autorização, concessão ou permissão, os serviços de telecomunicações, nos termos da lei, que disporá sobre a organização dos serviços, a criação de um órgão regulador e outros aspectos institucionais;

XII - (...)

a) explorar, diretamente ou mediante autorização, concessão ou permissão: a) os serviços de radiodifusão sonora e de sons e imagens; "

${ }^{14}$ Emenda Constitucional $n^{\circ} 9$, de 9 de novembro de 1995:

Art. $1^{\circ} \mathrm{O} \S 1^{\circ}$ do art. 177 da Constituição Federal passa a vigorar com a seguinte redação:

"Art. 177 (...)

$\S 10 \mathrm{~A}$ União poderá contratar com empresas estatais ou privadas a realização das atividades previstas nos incisos I a IV deste artigo observadas as condições estabelecidas em lei."

Art. $2^{\circ}$ Inclua-se um parágrafo, a ser enumerado como $\S 2^{\circ} \mathrm{com}$ a redação seguinte, passando o atual $\S 2^{\circ}$ para $\S 3^{\circ}$, no art. 177 da Constituição Federal:

"Art. 177 (...)

$\S 2 \circ \mathrm{A}$ lei a que se refere o $\S 1^{\circ}$ disporá sobre:

I - a garantia do fornecimento dos derivados de petróleo em todo o território nacional;

II - as condições de contratação;

III - a estrutura e atribuições do órgão regulador do monopólio da União". 
VIANA CUSTÓDIO, André; DA ROSA MOREIRA, Rafael Bueno. Revitimização de crianças e adolescentes em inquirições judiciais e violência institucional. Revista Eletrônica Direito e Política, Programa de Pós-Graduação Stricto Sensu em Ciência Jurídica da UNIVALI, Itajaí, v.16, n.1, 10 quadrimestre de 2021. Disponível em: www.univali.br/direitoepolitica - ISSN 1980-7791

$\mathrm{Na}$ cadeia produtiva dos serviços públicos teremos segmentos mais competitivos do que outros, sendo que a necessidade da regulação econômica diminui à medida que aumenta a concorrência no setor regulado. Ademais, nos setores característicos pelos monopólios naturais haverá maior competitividade e, outro aspecto que influencia o setor regulado é a tecnologia e a combinação de condicionantes.

Nesse sentido, a título de exemplo os setores de distribuição de energia e água, serviços que dependem de alto custo, acabam sendo monopólios naturais. Em contraponto os serviços de telecomunicações e gás natural são mais competitivos.

Os serviços públicos relacionados às atividades que envolvem infraestrutura, exigem um marco regulatório que gere uma política pública tarifária, que além do equilíbrio econômico e financeiro preveja prêmios pelo aumento da produtividade não apenas penalidades.

É sabido que tais benefícios podem gerar maior qualidade, maior diversidade nos serviços e modicidade das tarifas, tais políticas públicas vão gerar adaptações para o setor de regulação estatal.

A ação regulatória pode ser utilizada como um instrumento do aumento de eficiência e qualidade dos serviços prestados, fazendo com que os administradores públicos operem nas empresas monopolistas como se estivessem em um modelo privado concorrencial.

De modo geral a regulação econômica estatal reverbera-se na imposição de restrições quanto a preço, à quantidade, a entrada e saída do mercado, visando criar um mecanismo para corrigir falhas de mercado. As falhas de mercado estão ligadas ao poder de mercado, informações assimétricas, externalidades e bens públicos e se não tratadas devidamente pelo regulador, seus reflexos serão observados no bem-estar econômico social.

Outra característica da regulação é a característica de impor restrições e limitações por meios de normas e padrões aos agentes e empresas que 
VIANA CUSTÓDIO, André; DA ROSA MOREIRA, Rafael Bueno. Revitimização de crianças e adolescentes em inquirições judiciais e violência institucional. Revista Eletrônica Direito e Política, Programa de Pós-Graduação Stricto Sensu em Ciência Jurídica da UNIVALI, Itajaí, v.16, n.1, 10 quadrimestre de 2021. Disponível em: www.univali.br/direitoepolitica - ISSN 1980-7791

desempenham a função estatal. O Estado assume a responsabilidade pela prestação do serviço e transfere para a iniciativa privada a gestão e operação dos serviços, atuando como regulador.

\section{REGULAÇÃO ECONÔMICA POR INCENTIVOS}

Os tempos atuais testemunham, mutatis mutandi, os mesmos problemas econômicos e ambientais que passaram a acometer a humanidade desde a Revolução Industrial.

A partir da década de 80, o conceito de Desenvolvimento Sustentável surge e começa a ganhar força. Uma nova proposta desenvolvimentista para sociedade nasce com a publicação do relatório "Nosso Futuro Comum" pela Comissão Mundial sobre o Meio Ambiente e Desenvolvimento (Comissão Brundtland), sendo definido como aquele que atende às necessidades do presente, sem comprometer a possibilidade de as gerações futuras atenderem as suas próprias necessidades. (COMISSÃO MUNDIAL SOBRE O MEIO AMBIENTE E DESENVOLVIMENTO, 1991).

A busca pela eficiência econômica e bem-estar social, universalização de acesso e a redução de custos ambientais são tendências debatidas em todo mundo nas últimas décadas.

Diante de tal situação, alguns segmentos da economia começaram a estudar um modelo de regulamentação por incentivos. Para Sappington, a regulação por incentivos é definida como: "Incentive regulation can be defined as the implementation of rules that encourage a regulated firm to achive desired goals by granting some, but not complete, discretion to the firm"15.

A regulação por incentivo possui três características principais: I) definição de objetivos a serem atingidos; II) grau de liberdade na tomada de decisões e III)

\footnotetext{
15 SAPPINTON, David E. M. Designing Incentive Regulation. Review of Industrial Organization. V. 9, p 1994, p. 246. ("A regulamentação de incentivo pode ser definida como a implementação de regras que incentivam uma empresa regulamentada a atingir os objetivos desejados, concedendo à empresa uma certa discrição, mas não completa" - Tradução nossa).
} 
VIANA CUSTÓDIO, André; DA ROSA MOREIRA, Rafael Bueno. Revitimização de crianças e adolescentes em inquirições judiciais e violência institucional. Revista Eletrônica Direito e Política, Programa de Pós-Graduação Stricto Sensu em Ciência Jurídica da UNIVALI, Itajaí, v.16, n.1, $1^{\circ}$ quadrimestre de 2021. Disponível em: www.univali.br/direitoepolitica - ISSN 1980-7791

as ações de fiscalização do regulador vão se basear nos resultados operacionais ou no estabelecimento de metas associadas à qualidade e eficiência dos serviços prestados.

Insta destacar que o setor regulado tem em sua posse as melhores informações sobre o serviço prestado, tais como: custo, hábitos dos consumidores, crescimento do mercado, investimentos, tecnologias e etc. Informações que o próprio regulador não as tem, sendo que essas informações privilegiadas devem ser utilizadas com escopo no interesse da sociedade comum, ou seja, para reduzir custo, aumentar a qualidade e a eficiência dos serviços.

Outro ponto que chama atenção na regulação por incentivo é divergência entre os interesses da firma e da sociedade. Toda empresa tem como foco principal maximizar resultados, por outro lado os interesses da sociedade visam o bemestar coletivo. Ora, o marco regulatório do modelo de regulação por incentivos é justamente compatibilizar esses interesses conflitantes.

\section{REGULAÇÃO ECONÔMICA POR INCENTIVO NO BRASIL}

No Brasil, o processo de regulação econômica por incentivos tem como foco, a inserção de benefícios que garantam a isonomia fiscal e econômica, por meio de políticas públicas e sanções positivas.

Por sua vez, Leonardo Vizeu Figueiredo ${ }^{16}$, nos dá a seguinte definição:

Por incentivo, dentro do processo de regulação estatal, entende-se o auxílio prestado pelo Poder Público para o fomento, a implementação ou o desenvolvimento de determinadas atividades econômicas, a serem exploradas pelo particular. Em outras palavras, atividade implementada e exercida pela iniciativa privada, contando, todavia, com benefícios e incentivos estatais, conduzindo-se para o cumprimento dos interesses públicos e coletivos estabelecidos para tanto.

${ }^{16}$ FIGUEIREDO, Leonardo Vizeu. Lições de direito econômico. Rio de Janeiro: Forense, 2016, p.147 
VIANA CUSTÓDIO, André; DA ROSA MOREIRA, Rafael Bueno. Revitimização de crianças e adolescentes em inquirições judiciais e violência institucional. Revista Eletrônica Direito e Política, Programa de Pós-Graduação Stricto Sensu em Ciência Jurídica da UNIVALI, Itajaí, v.16, n.1, 10 quadrimestre de 2021. Disponível em: www.univali.br/direitoepolitica - ISSN 1980-7791

Partindo dessa premissa, verifica-se que o incentivo estatal nada mais é do que um benefício concedido visando garantir uma isonomia no plano econômico, bem como diminuir desigualdades econômicas e sociais.

No que tange à isonomia no plano econômico, insta destacar o princípio da igualdade de oportunidades, que nada mais é do que o acesso pelo menos favorecido a um determinado direito, este princípio é considerado uma das bases do Estado Democrático Social.

Os indivíduos são inseridos na sociedade utilizando a desigualdade como forma de equiparação, corrigindo uma desigualdade anterior, surgindo assim uma discriminação positiva.

Para Leonardo Vizeu Figueiredo o incentivo estatal é fundamental para redução de desigualdade regionais de cunho fiscal, in verbis:

Cumpre frisar, ainda, que a atividade de incentivo estatal é fundamental para redução das desigualdades regionais, uma vez que o desenvolvimento econômico não se dá de uma forma equivalente e uniforme em todas as regiões de um país. Destarte, cumpre ao Poder público, a fim de alcançar um nivelamento econômico e social em toda a nação, recorrer exatamente aos benefícios fiscais, reduzindo-se, gradativamente, as desigualdades. Observa-se que a redução das desigualdades sociais e regionais é um dos princípios da Ordem Econômica Brasileira (art. 170, VII), bem como um dos fundamentos da República (art. 30, III).

Outrossim, a própria Constituição da República veda a guerra fiscal entre os Estados-Membros, impedindo que, desta forma, o instituto de incentivos seja deturpado com o fim de mascarar disputas políticas internas, a teor do dispositivo do artigo 155 e parágrafos da Carta Política de outubro de 1988. 
VIANA CUSTÓDIO, André; DA ROSA MOREIRA, Rafael Bueno. Revitimização de crianças e adolescentes em inquirições judiciais e violência institucional. Revista Eletrônica Direito e Política, Programa de Pós-Graduação Stricto Sensu em Ciência Jurídica da UNIVALI, Itajaí, v.16, n.1, 10 quadrimestre de 2021. Disponível em: www.univali.br/direitoepolitica - ISSN 1980-7791

As mudanças nas regras de reajuste de fiscais acabam tendo impacto na regulação econômica, afetando assim os setores chaves da economia e consequentemente, o investimento em incentivos nos setores regulados.

Hodiernamente o Governo Federal utiliza de instrumentos tradicionais, como implementação por gestão direta e por uso de incentivos econômicos, bem como de mecanismos para ampliar a participação popular. Se utiliza também de políticas por gestão indireta, tais como: convênios e contratos, concessões de uso, transferências fundo a fundo e etc.

A título de exemplo de política pública criada com foco na regulação econômica por incentivo, temos o Programa de Incentivo à Implementação de Projetos de Interesse Social (PIPS), que foi criado por meio da Lei $\mathrm{n}^{\circ} 10.735$, de setembro de 2003, alterado pela lei $n^{\circ} 11.110$, de 25 de abril de 2005, sendo este um programa voltado à implementação de projetos "na área de desenvolvimento urbano e infraestrutura, saneamento básico, energia elétrica, gás telecomunicações, rodovias, sistemas de irrigação e drenagem, portos e serviços de transporte em geral, habitação, comércio e serviços"17 financiado pelas operações de crédito das instituições financeiras, tais como Fundo de Investimento Imobiliário (FII) e do Fundo de Investimento em Direitos Creditórios (FIDC).

Além das políticas públicas supramencionadas, vislumbra-se ainda a necessidade do investimento nas agências reguladoras em normas regulamentares referente ao incentivo de eficiência, ora a ampliação de princípios de tarifação para beneficiar as empresas com desempenho mais eficiente e penalizar as ineficientes.

17 Art. 40 da Lei no 10.735, de 11 de setembro de 2003: Art. 40 Fica o Poder Executivo autorizado a instituir o Programa de Incentivo à Implementação de Projetos de Interesse Social PIPS, voltado à implementação de projetos estruturados na área de desenvolvimento urbano em infra-estrutura, nos segmentos de saneamento básico, energia elétrica, gás, telecomunicações, rodovias, sistemas de irrigação e drenagem, portos e serviços de transporte em geral, habitação, comércio e serviços, por meio de Fundos de Investimento Imobiliário - FII, e de Fundos de Investimento em Direitos Creditórios - FIDC, lastreados em recebíveis originados de contratos de compromisso de compra, de venda, de aluguéis e de taxas de serviços, provenientes de financiamento de projetos sociais, com participação dos setores público e privado. 
VIANA CUSTÓDIO, André; DA ROSA MOREIRA, Rafael Bueno. Revitimização de crianças e adolescentes em inquirições judiciais e violência institucional. Revista Eletrônica Direito e Política, Programa de Pós-Graduação Stricto Sensu em Ciência Jurídica da UNIVALI, Itajaí, v.16, n.1, 10 quadrimestre de 2021. Disponível em: www.univali.br/direitoepolitica - ISSN 1980-7791

Norberto Bobbio ${ }^{18}$ no livro "A função promocional do direito", aborda os conceitos de sanção negativa e positiva da seguinte maneira:

Sanção negativa e positiva dão origem a duas relações distintas, nas quais as figuras do sujeito ativo (o titular do direito) e do sujeito passivo (o titular da obrigação) estão invertidas: no primeiro caso, a relação de direito-obrigação parte daquele que sanciona em direção aquele que é sancionado; no segundo, a mesma relação desloca-se daquele que é sancionado para aquele que sanciona em direção aquele que sanciona. Desejando expressar a situação do destinatário em ambos os casos, mediante a fórmula da norma condicionante (que não deve ser confundida com norma técnica, a qual veremos a diante), no primeiro caso, a formula é: "Se fazes $A$, podes $B$ "; ou seja, tens a obrigação de submeter-se ao mal da pena; no segundo, é: Se fazer A, podes B", isto é, tens o direito de obter o bem do prêmio.

Se considerarmos a realização ou não-realização de uma ação como condicionada à credibilidade da verificação de uma medida de desencorajamento ou de encorajamento, toda norma pode ser expressa pela fórmula de uma norma técnica, isto é, de uma norma que prescreve um meio adequado (a conduta prevista na norma primária) para atingir um determinado fim, o qual tanto pode ser evitar a desvantagem ameaçada quanto conquistar a vantagem prometida como secundária. Pois bem, a técnica de desencorajamento funciona com normas técnicas deste tipo: "Se não queres $A$, deves $B^{\prime \prime}$; a técnica de encorajamento, com normas deste tipo: Se queres $A$ deves $B^{\prime \prime}$.

Ora, diante de tal quadro se vislumbra a necessidade da utilização das técnicas de encorajamento na regulação econômica por incentivo no Brasil, as agências reguladoras ao invés de aplicar multas de grande vulto frente às irregularidades dos setores públicos, deviam criar instrumentos normativos que viabilizem vantagens para empresas que venham aderir projetos de que utilizem marcadores de eficiência.

18 BOBBIO, Norberto. Da estrutura à função: estudos de teoria do direito. Tradução Daniela Beccaccia Versiani. Barueri/SP: Manole, 2007. 
VIANA CUSTÓDIO, André; DA ROSA MOREIRA, Rafael Bueno. Revitimização de crianças e adolescentes em inquirições judiciais e violência institucional. Revista Eletrônica Direito e Política, Programa de Pós-Graduação Stricto Sensu em Ciência Jurídica da UNIVALI, Itajaí, v.16, n.1, 10 quadrimestre de 2021. Disponível em: www.univali.br/direitoepolitica - ISSN 1980-7791

\section{POLÍTICAS PÚBLICAS NO SETOR ECONÔMICO}

As políticas públicas têm relevante papel nos Estados Democráticos da atualidade e são vários os conceitos utilizados para traduzi-las.

O referido conceito foi sendo construído então desde o século XX com a contribuição de vários autores relevantes. Para um deles, Guy Peters, uma política pública seria "a soma das atividades dos governos, agindo diretamente ou através de delegação, que influenciam a vida dos cidadãos"19.

A temática teve por base o termo "policy analysis" para a qual não há tradução equivalente para o português, a não ser "política", e que para não a confundir com "politics", como designação distintiva, recepcionou a expressão "pública"20.

A sua construção se dá ao se conglobarem conhecimentos tanto científicos quanto acadêmicos, nas atuações do governo ${ }^{21}$. Então, pode se dizer que as políticas públicas são aquelas que traduzirão as intenções das autoridades governamentais em transformar algo no mundo real, através de diretrizes que norteiem a relação entre Estado e Sociedade em uma determinada área que necessite dessas alterações ou aperfeiçoamento.

O que ocorre, portanto, é uma sistematização de princípios que orientem algumas ações, podendo ser em documento no formato de ato normativo, programas, investimentos diretos, etc. Tal processo, conforme definira SARAIVA22, "(...) mostra-se como forma moderna de lidar comas incertezas decorrentes das rápidas mudanças do contexto".

\footnotetext{
19 PETERS, 1986 apud SOUZA, 2018, p. 13.

20 DIAS, Reinaldo e MATOS, Fernanda, Políticas Públicas - Princípios, Propósitos e Processos, São Paulo: Atlas, 2012, pp. 1 e 2 e SECCHI, Leonardo, Políticas públicas: conceitos, esquemas de análise, casos práticos. São Paulo: Cengage Leraning, 2012, p. 1 apud STUCKERT, Gabriel Fliege de Lucena. As Políticas Públicas e o Papel das Agências Reguladoras. Revista de Direito Sociais e Políticas Públicas, 2015, p. 291.

21 LASSWELL, 1936; SIMON, 1957 apud GIANEZINI; BARRETTO; LAUXEN; BARBOSA; VIEIRA, 2017, p. 1070.

22 (SARAIVA, 2006, p. 28 apud GIANEZINI; BARRETTO; LAUXEN; BARBOSA; VIEIRA, 2017, p. 1077)
} 
VIANA CUSTÓDIO, André; DA ROSA MOREIRA, Rafael Bueno. Revitimização de crianças e adolescentes em inquirições judiciais e violência institucional. Revista Eletrônica Direito e Política, Programa de Pós-Graduação Stricto Sensu em Ciência Jurídica da UNIVALI, Itajaí, v.16, n.1, 10 quadrimestre de 2021. Disponível em: www.univali.br/direitoepolitica - ISSN 1980-7791

Para Maria Paula Dallari Bucci (2002):

(...) políticas públicas são programas de ação governamental visando coordenar os meios à disposição do Estado e as atividades privadas, para a realização de objetivos socialmente relevantes e politicamente determinados ${ }^{23}$.

Assim, a função de elaborar essas políticas públicas, segundo Lehfeld ${ }^{24}$, se concentra no núcleo do Poder Executivo, ou seja no Presidente, o qual a compartilha e delega aos seus Ministros, conforme os seus ministérios e sua área de atuação.

No setor econômico, por exemplo, as "políticas públicas podem ser alcançadas pelas agências por meio de produção normativa, fiscalização e atos relacionados à outorga"25.

Em âmbito macroeconômico,

(...) o governo pode adotar uma política fiscal expansionista (diminuir tributação e/ou aumentar seus gastos para fomentar a produção) ou restritiva (aumentar a tributação e/ou diminuir seus gastos para conter a produção) ${ }^{26}$.

Esse tipo de escolha e decisão, a qual caberá a economistas e analistas do setor econômico, sempre refletirá diretamente no planejamento de políticas públicas

\footnotetext{
23 BUCCI, Maria Paula Dallari. Direito Administrativo e Políticas Públicas. São Paulo: Saraiva, 2002, p. 241.

24 LEHFELD, Lucas de Souza. Controle das Agências Reguladoras: A participação-cidadã como limite à sua autonomia. Tese de Doutorado em Direito - Pontifícia Universidade Católica de São Paulo - PUC, São Paulo, 2006, p. 286.

25 MARTINS, Marcio Sampaio Mesquita. Casos de políticas públicas implantadas por intermédio da regulação econômica. 2011. Disponível em: https://ambitojuridico.com.br/cadernos/direito-administrativo/casos-de-politicas-publicasimplantadas-por-intermedio-da-regulacao-economica/. Acesso em 26 de maio de 2020.

26 GUIMARÃES, Victor Chaves Ribeiro França. Políticas Públicas: Sua Importância no Desenvolvimento Econômico no País e das Empresas e seu Controle e Acompanhamento pelos Cidadãos, especialmente os Administradores. Disponível em <http://www.machadosobrinho.com.br/revista_online/publicacao/artigos/Artigo03REMS3.pdf> Acesso em: 30 maio de 2020.
} 
VIANA CUSTÓDIO, André; DA ROSA MOREIRA, Rafael Bueno. Revitimização de crianças e adolescentes em inquirições judiciais e violência institucional. Revista Eletrônica Direito e Política, Programa de Pós-Graduação Stricto Sensu em Ciência Jurídica da UNIVALI, Itajaí, v.16, n.1, 10 quadrimestre de 2021. Disponível em: www.univali.br/direitoepolitica - ISSN 1980-7791

para esse setor, "pois, se elas consomem necessariamente recursos, a propensão do governo de gastar mais ou menos influenciará em seu desenvolvimento"27.

Assim, a partir da criação das Agências Reguladoras no Brasil, ocorreram transformações de suma importância e as quais refletiram na administração bem como no processo de projeção e implementação de políticas públicas.

Os órgãos reguladores participam ativamente do processo de implementação de políticas públicas nos mais variados setores da economia. Esta atuação, inclusive, é bem variada podendo se expressar em atos normativos, executivos (licitações, outorgas, contratos), fiscalizatórios, etc., sendo certo que todos estão inseridos no contexto da função regulatória exercida pelas agências ${ }^{28}$.

Portanto, tem-se que políticas públicas se forem articuladamente bem implantadas com a participação das Agências Reguladoras intermediando o Executivo Central e os agentes econômicos (os responsáveis pela execução das mesmas) ${ }^{29}$, pode se vislumbrar relevantes transformações da atuação na ordem econômica do país, diminuindo-se os dispêndios financeiros com determinadas metas, como será posteriormente exemplificado.

\section{CONSIDERAÇÕES FINAIS}

A experiência regulatória para serviços públicos caracteriza-se pela busca permanente pelo Estado de minimizar custos e definir nível tarifário que atenda aos interesses do Governo Federal. Contudo, o papel de regulador leva a estabelecer preços que abarquem a manutenção do serviço com qualidade, quantidade e segurança necessária para a prestação do serviço.

\footnotetext{
27 Idem.

28 Idem.

29 MARTINS, Marcio Sampaio Mesquita. Casos de políticas públicas implantadas por intermédio da regulação econômica. $2011 . \quad$ Disponível em: https://ambitojuridico.com.br/cadernos/direito-administrativo/casos-de-politicas-publicasimplantadas-por-intermedio-da-regulacao-economica/. Acesso em 26 de maio de 2020.
} 
VIANA CUSTÓDIO, André; DA ROSA MOREIRA, Rafael Bueno. Revitimização de crianças e adolescentes em inquirições judiciais e violência institucional. Revista Eletrônica Direito e Política, Programa de Pós-Graduação Stricto Sensu em Ciência Jurídica da UNIVALI, Itajaí, v.16, n.1, $1^{\circ}$ quadrimestre de 2021. Disponível em: www.univali.br/direitoepolitica - ISSN 1980-7791

Restara evidente o importante papel das Agências Reguladoras como ferramentas na implementação das políticas públicas necessárias ao setor econômico, visto que podem possibilitar intervenção e atuação pelo Estado, evitando consideráveis custos de ordem financeira.

A regulação é um exercício de negociação política, visando que os reguladores entendam diferentes pontos de vista referente aos setores regulados para que assim possam sinalizar melhores com incentivos e penalidades na medida certa para que possam promover os resultados que reflitam o plano estratégico.

Assim, a análise da teoria econômica por incentivo é fundamental para o processo de elaboração de regras e procedimentos que garantam na ordem jurídica econômica a viabilização de políticas públicas que promovam o bemestar social e eficiência econômica.

\section{REFERÊNCIAS DAS FONTES CITADAS}

ANDRADE, Eduardo de Carvalho. Externalidades. In: ARVATE, Paulo Roberto; BIDERMAN, Ciro (Org.) Economia do setor público. Rio de Janeiro: Elsevier, 2004, p. $16-33$

ARAGÃO, Alexandre Santos de. Agências reguladoras e a evolução do direito administrativo econômico. Rio de Janeiro: Forense, 2004. P.37

BECKER, Gary S. A theory of competition among pressure group for political influence. Quarterly Jornal of Economics, no. 98,1983 p. 371-400

BERCOVICI, Gilberto. Constituição econômica e desenvolvimento: uma leitura a partir da constituição de 1988. São Paulo: Malheiros editores.

BOBBIO, Norberto. Da estrutura à função: estudos de teoria do direito. Tradução Daniela Beccaccia Versiani. Barueri/SP: Manole, 2007.

BUCCI, Maria Paula Dallari. Direito Administrativo e Políticas Públicas. São Paulo: Saraiva, 2002. 
VIANA CUSTÓDIO, André; DA ROSA MOREIRA, Rafael Bueno. Revitimização de crianças e adolescentes em inquirições judiciais e violência institucional. Revista Eletrônica Direito e Política, Programa de Pós-Graduação Stricto Sensu em Ciência Jurídica da UNIVALI, Itajaí, v.16, n.1, 10 quadrimestre de 2021. Disponível em: www.univali.br/direitoepolitica - ISSN 1980-7791

COASE, Ronald H. The Problem of Social Cost. The Journal of Law and Economicas. V. 3, p.1. 1960.

DI PIETRO, Maria Sylvia Zanello. Limites da função reguladora das agências diante do princípio da legalidade. In: DI PIETRO, Maria Sylvia Zanello (Coord.) Direito regulatório: temas polêmicos. 2ed. Belo Horizonte: Fórum, 2004.p.37

FIGUEIREDO, Leonardo Vizeu. Lições de direito econômico. Rio de Janeiro: Forense, 2016, p.147

GIANEZINI, Kelly. BARRETTO, Letícia Manique. GIANEZINI, Miguel Angelo. LAUXEN, Sirlei de Lourdes. BARBOSA, Gabriel Dario. VIEIRA, Reginaldo de Souza. Políticas Públicas: definições, processos e constructos no século XXI. Revista de Políticas Públicas. 2017. Disponível em: http://www.periodicoseletronicos.ufma.br/index.php/rppublica/article/view/8262. Acesso em: 27 de maio de 2020.

GRAU, Eros Roberto. A ordem econômica na constituição de 1988. São Paulo: Malheiros, 2005.

GRAU, Eros Roberto. O discurso neoliberal e a teoria da regulação. Desenvolvimento econômico e intervenção do Estado na Ordem Constitucional. Porto Alegre: Sergio Antonio Fabris, 1995.

IANNI, Octavio. Estado e planejamento econômico no Brasil. Rio de Janeiro: Civilização Brasileira, 1977.

JUSTEN FILHO, Marçal. O direito das agências reguladoras independentes. São Paulo: Dialética, 2002. p.15-16.

LEHFELD, Lucas de Souza. Controle das Agências Reguladoras: A participação-cidadã como limite à sua autonomia. Tese de Doutorado em Direito - Pontifícia Universidade Católica de São Paulo - PUC, São Paulo, 2006.

MARTINS, Marcio Sampaio Mesquita. Casos de políticas públicas implantadas por intermédio da regulação econômica. 2011. Disponível em: 
VIANA CUSTÓDIO, André; DA ROSA MOREIRA, Rafael Bueno. Revitimização de crianças e adolescentes em inquirições judiciais e violência institucional. Revista Eletrônica Direito e Política, Programa de Pós-Graduação Stricto Sensu em Ciência Jurídica da UNIVALI, Itajaí, v.16, n.1, 10 quadrimestre de 2021. Disponível em: www.univali.br/direitoepolitica - ISSN 1980-7791

https://ambitojuridico.com.br/cadernos/direito-administrativo/casos-de-politicaspublicas-implantadas-por-intermedio-da-regulacao-economica/. Acesso em 26 de maio de 2020.

NUSDEO, Fábio. Curso de economia: introdução ao direito econômico. São Paulo: Revista dos Tribunais, 2008

PERLINGIERI, Pietro. Il diritto dei contratti fra persona e mercato: problemi del diritto civile. Napoli: Edizine Scientifiche Italiane, 2003.

POSNER, Richard A. Theories of economic regulation. NBER,1974.p.12-13. (Working paper, n.41).

RAMOS TAVARES, André. Direito constitucional econômico. São Paulo: Método, 2006.

RAWLS, Jonh. Uma teoria da justiça. São Paulo: Editora Martins Fontes, 1997, p. 64-65

RODRIGUES, Jorge Martins. Política Tributária e Desenvolvimento Econômico. Aspectos da Política Tributária. Rio de Janeiro, Forum Roberto Simonsen, 1994.

RODRIGUES, Vasco. Análise económica do direito: uma introdução. Coimbra: Almedina, 2007.

SAPPINTON, David E. M. Incentives in Principal-Agente Relationships. The Journal Economics Perspectives, v. 5., p.45-66, 1991

SAPPINTON, David E. M. Designing Incentive Regulation. Review of Industrial Organization. V. 9, p 246, 1994

SOUZA, Celina. Coordenação de políticas públicas. Brasília: Enap - Escola Nacional de Administração Pública. ISBN: 978-85-256-0083-7, 2018.

STIGLER, George J. The Theory economic regulation. The Bell Journad of Economics and Management Science. V. 2, n.1.p.3, Spring, 1971. 
VIANA CUSTÓDIO, André; DA ROSA MOREIRA, Rafael Bueno. Revitimização de crianças e adolescentes em inquirições judiciais e violência institucional. Revista Eletrônica Direito e Política, Programa de Pós-Graduação Stricto Sensu em Ciência Jurídica da UNIVALI, Itajaí, v.16, n.1, 10 quadrimestre de 2021. Disponível em: www.univali.br/direitoepolitica - ISSN 1980-7791

STUCKERT, Gabriel Fliege de Lucena. As Políticas Públicas e o Papel das Agências Reguladoras. Revista de Direito Sociais e Políticas Públicas, Vol. I, p. 289 - 317. e-ISSN: 2525-9881, 2015.

Emendas Constitucionais Disponível em: http://www.planalto.gov.br/ccivil 03/Constituicao/Emendas/Emc/quadro emc.ht m Acesso em: 19 de julho de 2019.

RECEBIDO EM: JUN/2020

APROVADO EM: OUT/2020 